the whole, a tendency of the coefficients for cephalic index to be somewhat greater than their values as given by Galton's law. It is, therefore, reasonable to suppose that the heredity constant $\gamma$ (introduced in a paper 'On the Law of Ancestral Heredity') is not, as Mr. Galton takes it, unity, but has some slightly less value.

Other conclusions which may be drawn from the above table are :

(d) Among Indians of mixed blood the women are more brachycephalic and more variable than the men. This is in accordance with the general conclusion reached in a paper on 'Variation in Man and Woman,'* namely :

"The lower races give us results in sensible accordance with those we have drawn from the data for ancient civilizations, namely, the women are on the whole more brachycephalic and slightly more variable than the men."

(e) The younger generation is more brachycephalic and more variable than its parentage.

The whole of this difference can hardly be due to any change of shape of the skull with old age, for the majority of parents had in this case not passed the prime of life. It may be due to (i) a correlation between dolichocephaly and fertility or between dolichocephaly and philogamy, or (ii) more probably to the action of natural selection (results obtained, but not yet published, by the present writers show a correlation between physique and cephalic index), or (iii) to a greater or less admixture of white blood in the younger generation.

(f) Parents of sons are significantly less variable than parents of daughters. This is in accordance with the result previously obtained that mediocre fathers are likely to have sons, + but disagrees with the result

* Pearson, 'The Chances of Death,' Vol. 1, p. 370.

†'Phil. Trans.,' Vol. 187, A, p. 274. for stature-based on a far smaller probability - that mediocre mothers are likely to have daughters.

The conclusions of this paper, while appearing to the writers of interest, are to be taken, in the first place, as suggestions for much larger series of measurements and for new lines of investigation.

\section{A COMPLETE SKELETON OF TELEOCERAS THE TRUE RHINOCEROS FROM THE UPPER MIOCENE OF KANSAS.}

Together with the very full series of Upper Miocene skulls in the American Museum a complete skeleton of a rhinoceros representing an aged female of very large size, has recently been mounted. We used from materials belonging to several individuals secured by our excavations in Phillips Co., Kansas, under the direction of Dr. Wortman in the months of September, October and November, 1894.

The writer's attention was first drawn to the largely disregarded sexual and age characters of fossil Ungulates in studying the group of Titanotheres; the extinct rhinoceroses conform to the laws which were observed in that group, and which are familiar enough among living types, namely: males, of larger size with more robust and rugose skulls ; horns, if present, more prominent ; canines largely developed; incisors and anterior premolars disappearing in adults. By the comparison of the $\mathbf{1 6}$ skulls and 13 jaws, representing both sexes and all stages of growth, we are enabled for the first time to define positively the animal long known as Aphelops fossiger, to distinguish it both from Rhinoceros and Aceratherium, and to point out its important sexual and individual variations.

We owe to Hatcher the valuable demonstration that Aphelops fossiger bore a terminal horn upon the nasals, although he assigned this character to a type which he stapposed represented a new species, namely, 
Teleoceras major. Hatcher's type of T. major proves to be a middle-aged male of $A$. fossiger, and his distinction of Teleoceras as a genus supersedes Aphelops Cope, because Cope originally applied the term Aphelops to A. megalodus, defining it as an Acerathere with only three premolar teeth in the lower jaw. This is true of the type species ( $A$. megalodus), but this species should, so far as we know at present, be referred to the genus Aceratherium, in which the lower premolars vary from four to three in number according to age and individual variation, as in the living rhinoceros.

Our abundant material proves not only that Teleoceras is a rhinoceros with a median horn on the tips of the nasals, but that it is fully distinguished from the genus Rhinoceros as follows :

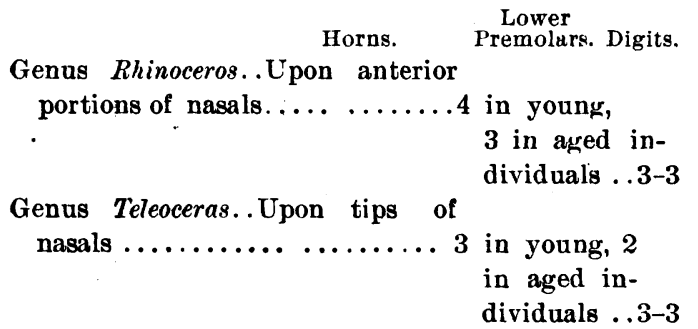

The reduction of the lower grinders to 5 in $T$. fossiger (as compared with 6 in $R h i$ noceros) is a very important and distinctive character, as it absolutely excludes Teleoceras fossiger from the ancestry of any of the modern rhinoceroses, and shows it to have represented a distinct side phylum.

EXCAVATION OF THE SKELETON.

The Phillips County Quarry, near Long Island, Kansas, was discovered in 1883 by Mr. Charles Sternberg; who collected for the University of Kansas and for the Harvard University Museum. From the latter collection Scott and Osborn procured materials for the restoration which they published in 1890. Subsequent collections were made by Sternberg and Hatcher for the United States Geological Survey, between 1884 and 1886 . Later Professor Cragin collected here, and in $1891 \mathrm{Mr}$. E. P. West, of the University of Kansas, aided by Mr. T. R. Overton, began the extensive collections which led to the preparation of the skeleton for the University under the direction of Professor Williston. This skeleton, as monnted in the Kansas Museum and described by Williston, gives a much more accurate idea of this animal than the previous restoration by Scott and Osborn, in which the chest is represented as far too shallow.

Its principal dimensions are as follows: Length, not including tail, $9 \mathrm{ft}$.; height, 4 ft.; greatest girth, $9 \mathrm{ft} .4$ in.

The measurements of the American Museum skeleton as mounted are: Length, $10 \mathrm{ft} .2$ in. to bend of tail ; height at withers, $4 \mathrm{ft} .1$ in.; greatest girth, $9 \mathrm{ft} .2 \mathrm{in}$.

From the above accounts, and especially from our own observations, it is seen that this quarry represents the deposit of some stream or small river along which the rhinoceroses herded in great numbers. In this typical bone-bed are mingled individuals of both sexes and of all sizes, and the proximity of one specimen to another is not a certain guide. There are certain spots, however, where considerable portions of individual skeletons have drifted together. We associate the skull and pelvis in our mounted specimen, for they are of similar age and were found within about six feet of each other, the skull being that of a fully adult female, and the pelvis indicating a corresponding age, because the ilia are united above the sacrum; with the pelvis, moreover, was found a part of the jaw belonging to the skull; also with this pelvis belong a femur, tibia and fibula, astragalus, calcaneum and cuboid of one side, several metacarpals and metatarsals and two cervical vertebre. The selection of the other limb and foot-bones was made from these as a guide. 
Similarly about 300 feet distant were found the principal ribs which have been selected for this mount, characterized by the very rugose appearance and oblique lines for the insertion of the abdominal muscles (sacro.lumbalis, longissinus dorsi). Near these ribs were large jaw and limb. correlation of material belonging to different individuals, this bone-bed gives evidence of the existence of only one species of rhinoceros, namely, T' fossiger. All the differences observed are due to growth, individual and sexual variations, as set forth below.

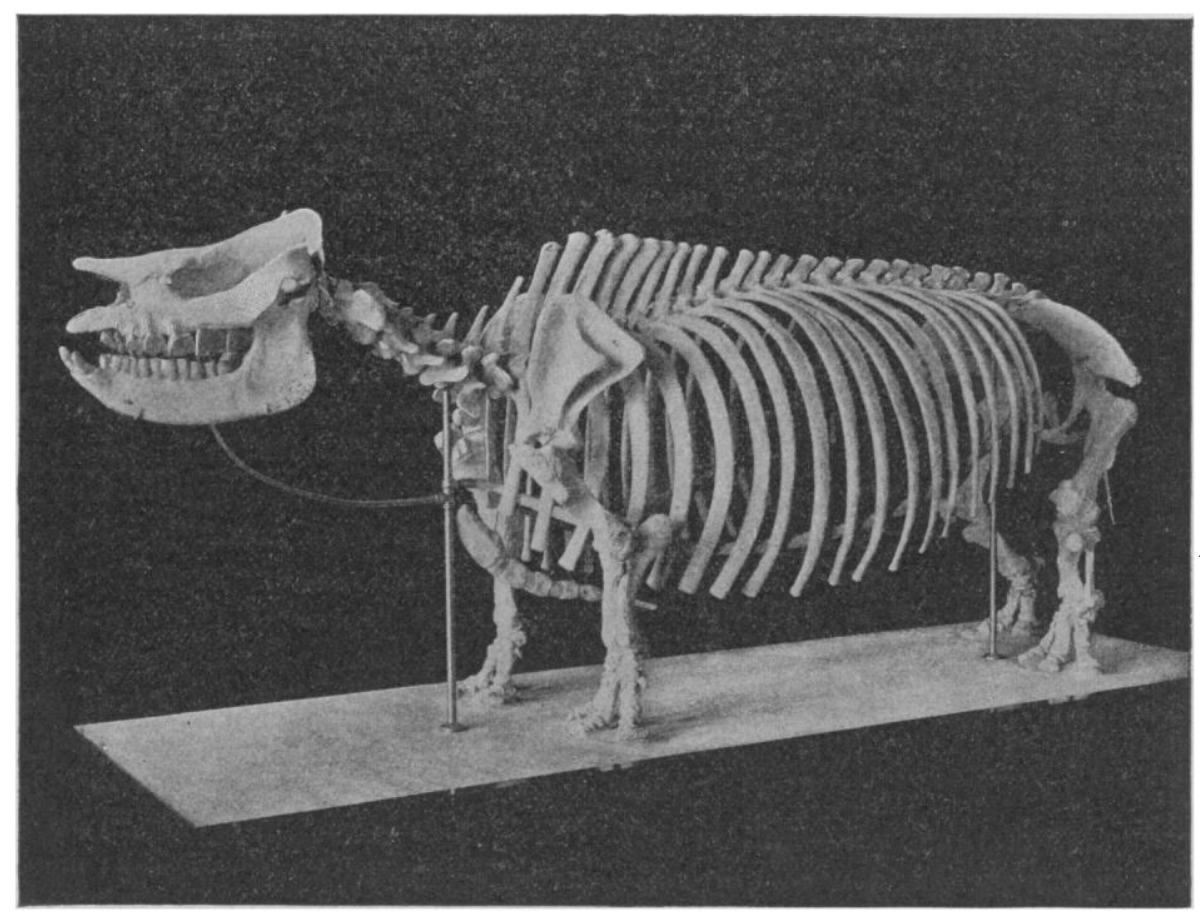

Fig. 1.-Mounted Skeleton of Teleoceras fossiger, one-twentieth natural size.

bones corresponding in size with those placed in the mounted skeleton. Apart from these probable associations, the main principle of selection adopted throughout has been that of the age and size standard, after a careful comparison of all the elements. In each region the largest and oldest bones were chosen. Upon this principle the ribs are shown to be of very great length; the chest girth exceeds that indicated in the Scott-Osborn restoration and equals that in the mount in the Kansas Museum, which has heretofore appeared extreme. In additional support of this
Comparative Measurements.

\begin{tabular}{|c|c|c|c|c|}
\hline & \multicolumn{2}{|c|}{$\begin{array}{l}\text { Teleoceras } \\
\text { fussiger. }\end{array}$} & \multicolumn{2}{|c|}{$\begin{array}{l}\text { Rhinnceros } \\
\text { indicus. }\end{array}$} \\
\hline & Feet. & |Meters. & Feet. & Meters. \\
\hline $\begin{array}{l}\text { Total length to bend of tail } \\
\text { Height, skull }\end{array}$ & $\begin{aligned} \text { 10. } 2 \\
4.1\end{aligned}$ & $\begin{array}{l}3.10 \\
1.23\end{array}$ & 10.8 & 3.05 \\
\hline Breadth, across pelivis.......... & $\begin{array}{l}3.111 / 2 \\
2.10 \\
2.11\end{array}$ & $\begin{array}{l}1.21 \\
0.87 \\
0.89\end{array}$ & $\begin{array}{l}5.61 / 2 \\
2.8\end{array}$ & $\begin{array}{l}1.69 \\
0.82\end{array}$ \\
\hline $\begin{array}{l}\text { Fore } \operatorname{limb}_{\text {, total flexed ibail }} \\
\text { of hum. vert. to ground } \\
\text { Hind limb. total flexed (bali } \\
\text { of femur vert. } t \text { ' ground. }\end{array}$ & $\begin{array}{l}2.11 \\
2.71 / 2\end{array}$ & $\begin{array}{l}0.7 \\
0.8_{0}\end{array}$ & $\begin{array}{l}3.5 \\
3.81 / 2\end{array}$ & $\begin{array}{l}1.04 \\
1.13\end{array}$ \\
\hline
\end{tabular}

From the above measurements it appears that from head to tail $T$. fossiger is only six inches shorter than $R$. unicornis, while the back is eighteen inches (.580 $\mathrm{mm}$.) nearer 
the ground. This remarkable lowering of the trunk is chiefly caused by the great reduction of the fore arm, fore leg and metapodials. The bumerus and femur are respectively only 90 and $110 \mathrm{~mm}$. shorter than in $R$. unicornis, while the radius and tibia (typically shorter elements) are respectively 140 and $130 \mathrm{~mm}$. shorter, and the metacarpals and metatarsals are respectively 90 and $950 \mathrm{~mm}$. shorter. This limb reduction is very striking. At the saine time the abdominal girth exceeds that of $R$. unicornis, justifying Cope's conclusion that this animal had rather the proportions of the hippopotamus than of the rhinoceros. It will be recalled that $R$. unicornis has a lower abdominal line than $R$. sondaicus or $R$. sumatrensis, or than either of the African rhinoceroses. $T$. fossiger, therefore, had a totally different external appearance from any existing form.
R. unicornis, although less pitched forward. The limbs are much shorter than in any living type, and, as pointed out by Pavlow, at once recall those of $R$. brachypus and $R$. aurelianensis. A further comparison of $T$. fossiger strengthens the resemblance to the latter form. The proportions of the skull, limbs and metapodials are very similar. In both the cnemial crest of the tibia is double; the secondary folds of the superior molars are similar, as well as the general form of the skull.*

Henry F. Osborn.

\section{A NATURAL BRIDGE IN UTAH.}

The remarkable natural bridge illustrated in this article has, so far as I know, never been called attention to before, and is, therefore, entitled to rank as a new discovery among the curiosities of nature. It is an object rivaling the celebrated natura

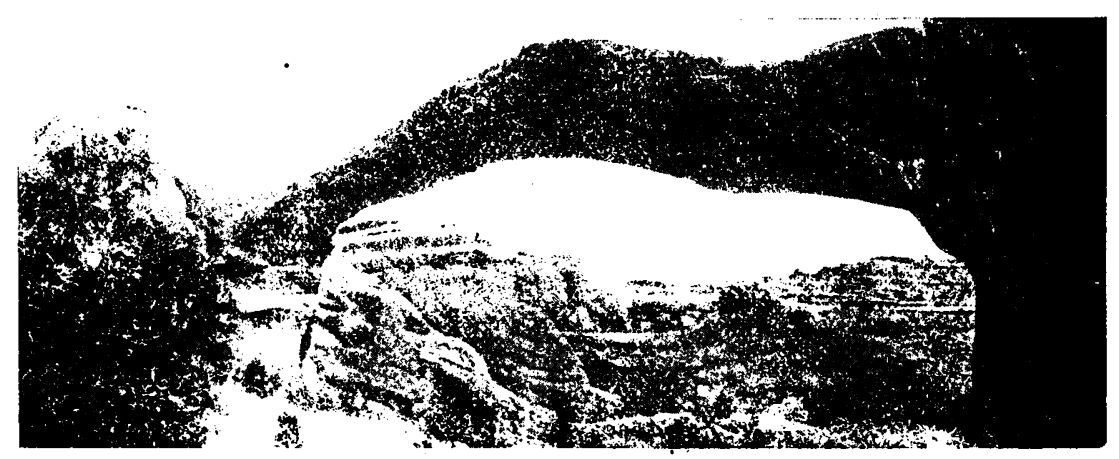

FIG. 1.

It may be briefly characterized as a brachycephalic, extremely short-limbed rhinoceros, partly aquatic in its habits, with a very large brain and no diploë of the skull. It parallels the African rhinoceroses $R$. simus and $R$. bicornis, in the form of the humerus, femur and atlas, and in the terminal position of the nasal horn. The occiput, however, is widely different from that of the African rhinoceroses, as well as of $R$. sumatrensis, resembling rather that of bridge of Virginia in magnitude and even exceeding that classic in interest when one considers its probable origin.

The view was taken in southeastern Utah not far from Moab, on the Grand River, in the midst of the great arid region lying west of the Rocky Mountains and some fifty miles from any railway. It was not my good fortune to be able to visit the lo-

* Bulletin American Museum of Natural History, March 18, 1898. 